desperate need for due rationalization in the use of the Amazon region's resources. To reach such a goal, it is necessary to strengthen the environmental laws and include higher penalties for those who burn more than a permissible area of forest that is found on their properties. In addition, a complete halt is urgently needed in the official support given to the immigration of workers from southern Brazil to the north - a process that has been taking place for more than a decade. These workers, attracted by offers of free land and by the richness of minerals in the area, exert strong pressures on the region's environment, being to some extent responsible for the burning of the Brazilian rain-forests.

The second major challenge faced by Brazil's new President is to ensure that the population of native 'indians' who inhabit the country's rain-forests are not destroyed either by the disappearance of their local environment (for example, by the building of dams), or by the white man's practices. Brazil's 'indian' population today is just over 200,000 , compared with the estimated 6 millions who were found by the Portuguese when they started to explore the country in the year 1500 . Over the past five years, a growing number of 'indians', from several Amazon tribes, have been killed in conflicts involving farmers and gold-diggers. The invasion of the "indians", territory for the exploitation of gold is a common practice in the region, and, not being armed or able to defend themselves, the 'indians' stand very little chance of survival.

The above problems are added to by an exacerbation of the country's economic difficulties which, in the past, were lightened by making use of the Amazon region's richness - especially of the rain-forests, which provided an easy source of hard cash. With the attention with which the international community now looks at developments in the region, such a soft choice is no longer tolerable. The fact that widespread destruction of rain-forests can lead to major ecological changes world-wide, implies that greater care than hitherto should in the future be taken in treating 'rain-forests-related issues'. Due to the amount and variety of pressures that are being placed on the country's forest ecosystems, the Brazilian President is under a test such as no head of state would wish to be submitted to.

The future will tell how 'green' is Brazil's new President, and how successful the policies which his government adopts in relation to the Brazilian rain-forests really are. Meanwhile the international scientific community has a major role to play: as in the past, when all of us were keen on pointing out mistakes, we should also support authentic progress and stimulate those who are really working for the reduction of the seriousness of one of today's major environmental problems.

Walter D.S. Leal Filho, Coordinator International Tropical Rain-forests Awareness Programme Institut für Erziehungswissenschaft Universität Hamburg Sedanstrasse 19 D-2000 Hamburg 1.3 Germany

\title{
Institute for the Study of Natural Systems
}

The Institute for the Study of Natural Systems is a nonprofit, tax-exempt, education and research organization which seeks to find new and innovative approaches to increasing harmony between people and Nature from a psychological standpoint. Current projects include:

1. The Spirit of Place Symposia: - Begun in 1988, this is a five-years' series of annual public symposia which bring together representatives of indigenous peoples to meet with modern designers, scientists', lawyers, and artists, to explore the nature of traditional Earth wisdom and its value to modern society's quest for finding ways to create sustainability. The first two programmes, held in 1988 at the University of California at Davis and in 1989 at Grace Cathedral in San Francisco, California, each featured 60 speakers. Proceedings from these presentations will be published by Quest Books in the spring of 1991 as a popular anthology, The Spirit of Place: Sacred Places and Spaces. Symposium co-producer James A. Swan, PhD, an environmental psychologist, also recently published Sacred Places: How The Living Earth Seeks Our Friendship (1990), which reflects on the spirit of place programme and 15 years' prior study of sacred space and its value to ancient and modern times.

The 1990 Spirit of Place symposium is being held at Mesa Verde National Park in Colorado, September 18-23, with many tribes of the Southwest sharing their traditional land heritage with park managers, architects, designers, and attorneys, in search of new ways to create sustainable cities and communities.

The 1991 Spirit of Place symposium will examine the peoples of the Pacific Rim, especially rain-forest cultures, and the 1992 programme will be held in Washington, DC, addressing public policy and urban design outcomes of the series of symposia.
2. 'Mr Recycleman' : - A recycling mascot to promote citizen participation in curbside recycling and litter-control programmes. The design for this loveable character comes from a county-wide children's art contest in Marin County, California, with the winning drawing by an eight-years'old boy. The actual character, who tours California at public events, was built by costume designers from Lucasfilm's award-winning 'Industrial Light and Magic'. A music video and musical comedy starring 'Mr Recycleman' are currently in preparation.

3. The Celebration for Mother Earth Concert: - A large public musical concert aimed at communicating mythic stories of traditional cultures in concert with popular musical treatments by well-known artists. The first concert was held at Grace Cathedral in San Francisco in August of 1989, featuring Steven Halpern and the undersigned, with members of 12 different Amerindian tribes recreating the creation myth of the Hopi Indian tribe. The second concert is slated for 14 December 1990 in San Francisco, featuring the music of Pete Sears' 'Watchfire' album which also features Jerry Garcia, Mickey Hart, Mimi Farina, Holly Nears, and yet others. This second programme will be a benefit performance for the Sioux Indian 'nation'.

Support for programmes of the Institute for the Study of Natural Systems has come from: The Beldon Fund, the JRH Foundation, Joshua Mailman, Laurance Rockefeller, The Skaggs Foundation, Lucasfilm Ltd, and Smith \& Hawken.

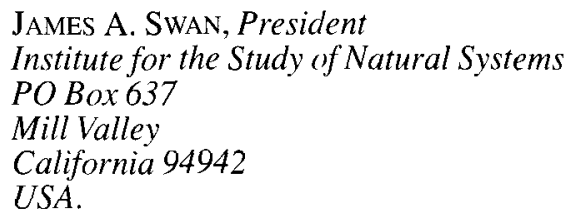

USA. 